University of the Pacific

Scholarly Commons

All Faculty Articles - School of Engineering and Computer Science

All Faculty Scholarship

$1-1-1992$

\title{
Total internal reflection fluorescence microscopy (TIRFM) ii. Topographical mapping of relative cell/substratum separation distances
}

\author{
George A. Truskey \\ Duke University \\ Jeffrey S. Burmeister \\ Duke University, jburmeister@pacific.edu \\ E. Grappa \\ Duke University \\ William M. Reichert \\ Duke University
}

Follow this and additional works at: https://scholarlycommons.pacific.edu/soecs-facarticles

Part of the Engineering Commons

\section{Recommended Citation}

Truskey, G. A., Burmeister, J. S., Grappa, E., \& Reichert, W. M. (1992). Total internal reflection fluorescence microscopy (TIRFM) ii. Topographical mapping of relative cell/substratum separation distances. Journal of Cell Science, 103(2), 491-499.

https://scholarlycommons.pacific.edu/soecs-facarticles/38

This Article is brought to you for free and open access by the All Faculty Scholarship at Scholarly Commons. It has been accepted for inclusion in All Faculty Articles - School of Engineering and Computer Science by an authorized administrator of Scholarly Commons. For more information, please contact mgibney@pacific.edu. 


\title{
Total internal reflection fluorescence microscopy (TIRFM)
}

\section{II. *Topographical mapping of relative cell/substratum separation distances}

\author{
G.A. TRUSKEY, J.S. BURMEISTER, E. GRAPA and W.M. REICHERT ${ }^{\dagger}$ \\ Department of Biomedical Engineering and Center for Biochemical Engineering, Duke University, Durham, NC 27706, USA \\ *Paper I in this series is Reichert and Truskey (1990) \\ $\dagger$ Author for correspondence
}

\section{Summary}

A simplified model of TIRF optics was used to quantitate the relative membrane/substratum separation distances from the spatial pattern of TIRF image brightness. Phase-contrast and total internal reflection fluorescence microscopy (TIRFM) images were collected of bovine aortic endothelial cells (BAEC) plated onto glass microscope slides for $15 \mathrm{~min}, 30 \mathrm{~min}$ and $24 \mathrm{~h}$. BAEC adherent for $15 \mathrm{~min}$ showed an absence of a focal contact morphology, with the region of closest apposition beneath the cell center. After 30 min, multiple contacts with the surface were established and the morphology became more irregular. BAEC attached for 24 h showed well-defined focal contact regions aligned in characteristically striated patterns. The relative distance between closest and farthest membrane/substratum separations are consistent with reported distance between focal and matrix contacts. Topographical maps of membrane/substratum separation distances over the entire ventral surface of the plated cells were constructed to demonstrate the utility of quantitative TIRF microscopy.

Key words: TIRF, cell adhesion, cell membrane.

\section{Introduction}

Focal contacts are narrow regions of an adherent cell membrane (e.g. $0.2 \mu \mathrm{m} \times 10 \mu \mathrm{m}$ ) that come within $10-15 \mathrm{~nm}$ of the substratum surface. Close contacts designate membrane/substratum separations of 15-50 nm. Extracellular matrix contacts refer to regions of the cell membrane separated from the substratum by $100 \mathrm{~nm}$ or more (Burridge et al., 1988; Izzard and Lochner, 1976; Chen and Singer, 1982). It is known that (i) actin fibers terminate at focal contacts and provide structural support for the cells; (ii) morphological and functional studies indicate that focal contacts are the sites of strongest cell adhesion to the surface (Burridge et al., 1988); and (iii) the lifetime of individual focal contacts on nonmotile cells is highly variable and remodeling of adhesion sites occurs as the cell responds to a variety of environmental stresses (Burridge et al., 1988; Roboteskewyj et al., 1991). The role of close and extracellular matrix contacts in cell adhesion is less well understood; but these regions may also provide some adhesion, albeit weaker. The optical techniques of interference reflection microscopy (Gingell and Todd, 1979) (IRM) and total internal reflection fluorescence microscopy (Axelrod et al., 1982) (TIRFM) have proven useful in visualizing these contact regions. However, a recent theoretical treatment of these types of microscopy from Gingell et al. (1987) indi- cates that TIRFM optics are significantly more sensitive than IRM to the small fluctuations in the contour of the membrane/substratum contact regions.

Briefly, the total internal reflection of visible light at the solid/liquid interface produces a region of optical intensity, i.e. the "evanescent wave", that penetrates just a few tenths of a micrometer into the liquid phase. This interfacially constrained optical field is the basis of all total internal reflection and attenuated total reflection types of spectroscopy, spectrometry and microscopy (Reichert, 1989). In principle, the only species observed under TIRF optics are those that (i) are intrinsically or extrinsically fluorescent and (ii) lie close enough to the solid/liquid interface to be within the region illuminated by the evanescent wave.

Most applications of TIRFM to image cell/substratum contacts for a number of cell types have been qualitative (Todd et al., 1988; Lanni et al., 1985; Gingell et al., 1985; Axelrod et al., 1986; Nakache et al., 1986; Weis et al., 1982). However, Lanni et al. (1985)used photometric readings of TIRF-illuminated 3T3 fibroblast cells excited at two different angles of incidence to calculate cell/substratum separation distances of $49 \mathrm{~nm}$ for focal contacts and $69 \mathrm{~nm}$ for close contacts. Their approach was limited to small regions of the cell and was computationally cumbersome, requiring solution of the matrix equations describing the electromagnetic field in a region containing four optically 
different materials (glass, aqueous solution, membrane and cytoplasm). Nevertheless, this work clearly demonstrated that TIRF images can be quantified. An improved method of quantifying TIRFM should provide more definitive information on the topography of the ventral surface of the cell, particularly in terms of the dynamics of focal contact formation/disruption in response to physical forces and the effect of surface properties on cell adhesion.

In the current paper, digitized phase-contrast and TIRFM images of bovine aortic endothelial cells (BAEC) plated onto glass microscope slides were collected using a thermoelectrically cooled CCD detector. Cells were plated for $15 \mathrm{~min}, 30 \mathrm{~min}$ and $24 \mathrm{~h}$ to yield contact morphology that lacks (15 min and $30 \mathrm{~min}$ ) and possesses (24 h) focal contact structures on the ventral surface of the cell membrane. Membrane/substratum separation distances were calculated from TIRFM images using a simplified theory of TIRFM of cells (Reichert and Truskey, 1990) that permits the straightforward calculation of separation distances. The resulting separation distance contours are consistent with results obtained from scanning electron microscopy and immunofluorescent vinculin staining of focal contacts. The spatial distribution of the cell/substratum separations were categorized into focal, close and extracellular matrix contact regions, which were used to construct a topographical map of the entire ventral surface of the adherent cell.

\section{Theory}

Consider an anchorage-dependent cell adherent to the aqueous side of the glass/aqueous interface that is illuminated by the evanescent wave of a total internal reflected incident light beam (Fig. 1). Recently, we used numerical calculations to show that one can neglect the refractive index discontinuity presented by the $4 \mathrm{~nm}$ thick cell membrane, assign an effective cellular refractive index to the interfacial region, and use the expressions that govern a simple dielectric interface to measure accurately the evanescent intensity penetrating the surface-adherent cell (Reichert and Truskey, 1990). From this analysis it was shown that the TIRFM image of a dye-labelled cell membrane should have a spatially variant brightness $F\left(x, y, \theta_{\mathrm{i}}\right)$ that follows a simple exponential:

$$
F\left(x, y, \theta_{\mathrm{i}}\right)=\mathrm{K} d_{\mathrm{f}} T\left(\theta_{\mathrm{i}}\right) \exp \left[-\Delta(x, y) / d_{\mathrm{p}}\left(\theta_{\mathrm{i}}\right)\right],
$$

where $x, y$ are lateral coordinates in the image plane, $\theta_{\mathrm{i}}$ is the incident angle of total internal reflection, $\mathrm{K}$ is an instrumental and experimental constant, $d_{\mathrm{f}}$ is the membrane thickness, $\Delta(x, y)$ is the membrane/substratum separation distance (Fig. 1), and $T\left(\theta_{\mathrm{i}}\right)$ and $d_{\mathrm{p}}\left(\theta_{\mathrm{i}}\right)$ are the Fresnel transmission coefficient and depth of penetration of a totally reflected light beam at a simple dielectric interface. For TE polarized light we may write (Reichert and Truskey, 1990):

$$
T\left(\theta_{\mathrm{i}}\right)=\frac{4 \cos ^{2} \theta_{\mathrm{i}}}{1-\left(n_{\mathrm{eff}} / n_{\mathrm{g}}\right)^{2}}
$$

$$
d_{\mathrm{p}}\left(\theta_{\mathrm{i}}\right)=\frac{\lambda}{4 \pi n_{\mathrm{i}} \sqrt{\sin ^{2}} \overline{\theta_{\mathrm{i}}-\left(n_{\text {eff }} / n_{\mathrm{g}}\right)^{2}}}
$$

where $\lambda$ is the wavelength of the incident radiation, $n_{\mathrm{g}}$ is the glass refractive index, and $n_{\text {eff }}$ is the effective refractive index of the adherent cell.

Fig. 2 presents a hypothetical illustration of what one might expect from a TIRFM experiment of an anchoragedependent cell with a fluorescently labelled membrane. Fig. 2 A contains a $2 \pi \times 2 \pi$ section of the cell membrane with a membrane/substratum separation distance that varies sinusoidally according to the expression:

$$
\Delta(x, y)=100\left[\cos ^{2}(x)+\cos ^{2}(y / 2)\right] \mathrm{nm},
$$

where $0 \leq x, y \leq 2 \pi$. For an effective cellular refractive index of 1.38 and a glass refractive index of 1.51 , a critical angle for total internal reflection of $\theta_{c}=\sin ^{-1}(1.38 / 1.51)=66$ degrees is calculated (Bereiter-Hahn et al., 1979; unpublished observations). For an incident angle of 70 degrees, from equations (2) and (3), we calculate $T\left(\theta_{\mathrm{i}}\right)=2.840$ and $d_{\mathrm{p}}\left(\theta_{\mathrm{i}}\right)=122.55 \mathrm{~nm}$ for TE polarized $514.5 \mathrm{~nm}$ incident radiation. Substituting these values into equations (4) and (1), and evaluating, yields the 3D TIRFM image, shown in Fig. $2 \mathrm{~B}$, that is expected when the cell membrane is evanescently illuminated at an incident angle of 70 degrees.

From Fig. 2 it is clear that TIRF is a nonlinear optical transformation, or mapping, of the cell/substratum separation distances into a spatial pattern of image brightnesses, with the brightest regions of the image corresponding to the regions of the membrane in closest apposition to the substratum surface. Conversely, the inverse transformation (i.e. $\mathrm{TIRF}^{-1}$ ) when operated upon the spatial distribution of image brightnesses provides a 3D conformal mapping of the membrane/substratum separation distances over the ventral surface of the adherent cell. Therefore, if the forward TIRF transform is defined as:

$$
\operatorname{TIRF}[\Delta(x, y)]=F\left(x, y, \theta_{\mathrm{i}}\right)
$$

then the reverse transform is simply the inverse:

$$
\operatorname{TIRF}^{-1}\left[F\left(x, y, \theta_{\mathrm{i}}\right)\right]=\Delta(x, y)
$$

where from equation (1)

$$
\Delta(x, y)=d_{\mathrm{p}}\left(\theta_{\mathrm{i}}\right)\left\{\ln \left[\mathrm{K} d_{\mathrm{f}} T\left(\theta_{\mathrm{i}}\right)\right]-\ln \left[F\left(x, y, \theta_{\mathrm{i}}\right)\right]\right\} .
$$

If one assumes that the membrane does not approach the substratum any closer than some minimum distance greater than zero, then the membrane/substratum separation can be written as $\Delta(x, y)=\Delta_{0}+\delta(x, y)$, where $\Delta_{0}$ is the minimum separation distance and $\delta(x, y)$ is the increased membrane separation beyond $\Delta_{\mathrm{o}}$ (e.g. for $\Delta_{\mathrm{o}}=15 \mathrm{~nm}, \Delta(x, y)=30 \mathrm{~nm}$ corresponds to $\delta(x, y)=15 \mathrm{~nm})$. Substituting this modification into equations (1) and (7), and setting the incident angle to a constant value, yields:

$$
F(x, y)=F_{\mathrm{o}} \exp \left[-\delta(x, y) / d_{\mathrm{p}}\right]
$$




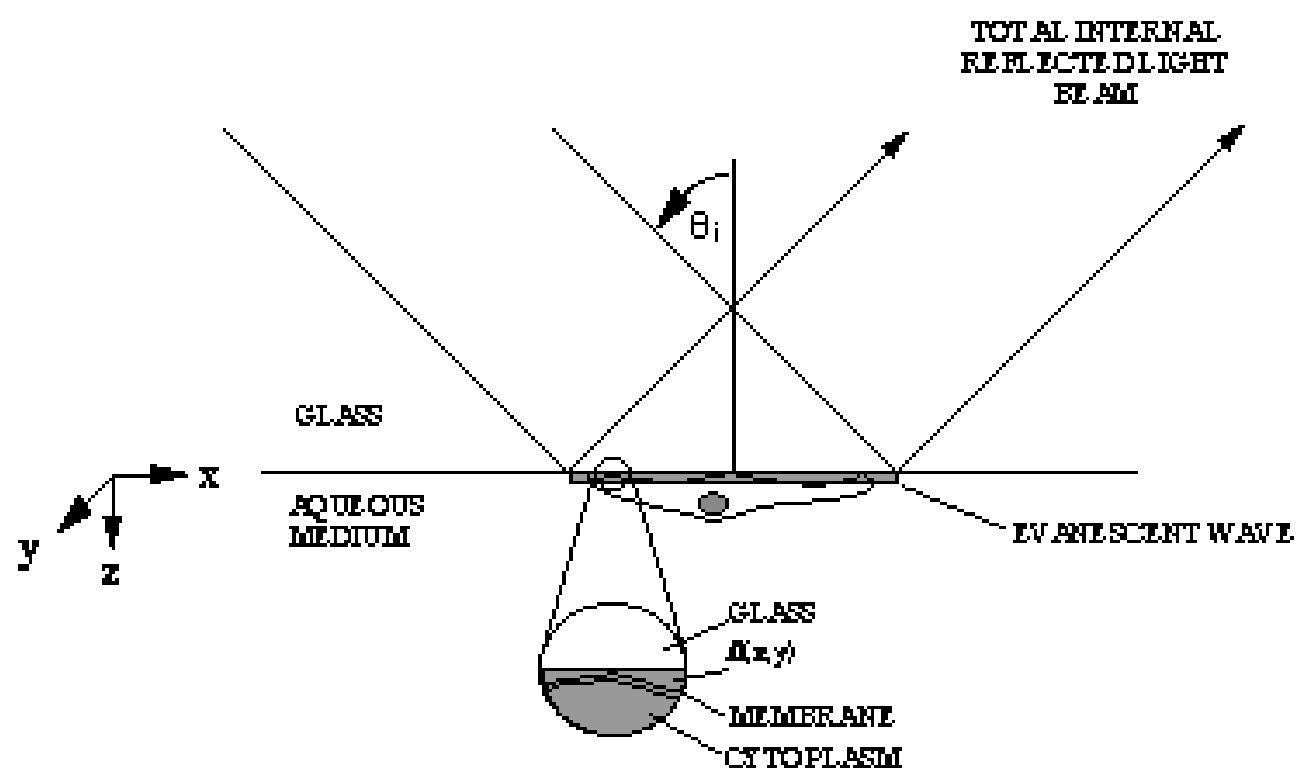

Fig. 1. Schematic drawing of an anchorage-dependent cell adherent to the aqueous side of the glass/aqueous interface that is illuminated by the evanescent wave of a total internal reflected light beam.

$$
\Delta(x, y)=\Delta_{\mathrm{o}}+d_{\mathrm{p}} \ln \left[F_{\mathrm{o}} / F(x, y)\right]
$$

where $F_{\mathrm{o}}=\mathrm{K} d_{\mathrm{f}} T \exp \left[-\Delta_{\mathrm{o}} / d_{\mathrm{p}}\right]$ is the maximum image brightness corresponding to the minimum membrane substratum separation and $\mathrm{K}, d_{\mathrm{f}}, T$ and $d_{\mathrm{p}}$ are as defined for equations (1)-(3).

\section{Materials and methods}

\section{Preparation of hydrophilic glass substrata}

All substrata were standard 1 in $\times 3$ in $\times 1 \mathrm{~mm}$ soda lime glass microscope slides (Goldseal, Clay Adams, Lincoln Park, NJ). Glass slides were sonicated in 5\% PCC-54 cleaning solution (Pierce, Rockford, IL) for $3 \mathrm{~h}$, followed by rinsing with copious amounts of distilled deionized water (Milli Q, Millipore Inc.) and dried overnight at $150^{\circ} \mathrm{C}$.

\section{Cell culture}

Bovine aortic endothelial cells (BAEC) were isolated from fetal calf aortas by mechanical scraping. The cells were maintained in an incubator at $37^{\circ} \mathrm{C}$ in an atmosphere of $5 \%$ $\mathrm{CO}_{2}$ and 95\% air in Dulbecco's Modified Eagle's Medium (DMEM, Sigma Chemical, St. Louis, MO) supplemented with $10 \%$ fetal calf serum, 100 i.u. $/ \mathrm{ml}$ penicillin, $0.1 \mathrm{mg} / \mathrm{ml}$ streptomycin, and $0.25 \mu \mathrm{g} / \mathrm{ml}$ amphotericin B. Upon reaching confluence, primary cultures were subcultured by splitting 1:3 and cells were used in passages 2 through 10. Cells in a $75 \mathrm{~cm}^{2}$ flask were incubated with $1.5 \mathrm{ml}$ trypsin/EDTA (Biofluids, Inc., Rockville, MD) for $10 \mathrm{~min}$ at $37^{\circ} \mathrm{C}$, resuspended in DMEM containing $10 \%(\mathrm{v} / \mathrm{v})$ calf serum $(\mathrm{CS})$ and diluted to approximately $8 \times 10^{4}$ cells $/ \mathrm{ml}$.

Fibronectin (Fn) was isolated from fresh human plasma by gelatin-agarose affinity chromatography (Ruoslahti et al., 1982), and equilibrated with $0.1 \mathrm{M} \mathrm{NaCl}, 50 \mathrm{mM}$ Tris$\mathrm{HCl}, \mathrm{pH} 7.4$, by dialysis. Purity was assessed by SDS/polyacrylamide gel electrophoresis. The protein concentration was determined spectrophotometrically at $280 \mathrm{~nm}$ using a molar absorption coefficient of $5.63 \times 10^{5} \mathrm{M}^{-1} \mathrm{~cm}^{-1}$ for a Fn molecular mass of $440 \mathrm{kDa}$ (Yamada, 1982). Hydrophilic glass microscope slides were incubated with $10 \mu \mathrm{g} / \mathrm{ml} \mathrm{Fn}$ in $0.1 \mathrm{M} \mathrm{NaCl}, 50 \mathrm{mM}$ Tris-HCl, $\mathrm{pH} 7.4$, for $1 \mathrm{~h}$ at room temperature and then rinsed twice with sterile $0.1 \mathrm{M} \mathrm{NaCl}, 50 \mathrm{mM}$ Tris- $\mathrm{HCl}, \mathrm{pH} 7.4$, yielding an adsorbed Fn concentration determined by radiolabeling to be $148 \pm 13$ $\mathrm{ng} / \mathrm{cm}^{2}$ using the protocol described by Truskey and Pirone (1990). Immediately following preadsorption, the Fntreated glass slides were plated with BAEC in $10 \% \mathrm{CS}-$ DMEM at $37^{\circ} \mathrm{C}$ for $15 \mathrm{~min}, 30 \mathrm{~min}$ or $24 \mathrm{~h}$.

\section{Cell membrane labelling}

After plating, the medium was removed, the adherent cells were rinsed twice with Hanks' balanced salt solution (HBSS, Sigma Chemical, St. Louis, MO) and then fixed with a solution of $3.75 \%(\mathrm{v} / \mathrm{v})$ formaldehyde in phosphate buffered saline (PBS) for $10 \mathrm{~min}$ at room temperature. The fixed cells were rinsed in distilled sterile water, and then stored in $25 \mathrm{ml}$ of distilled water. Cell membranes were fluorescently labelled by adding $1.25 \mathrm{ml}$ of a $3 \mathrm{~g} / \mathrm{l}$ solution of 1,1'-dioctadecyl-3,3,3',3'-tetramethylindocarbocyanine perchlorate (DiIC18(3); Molecular Probes, Inc., Eugene, OR) in ethanol to the fixed cells for $20 \mathrm{~min}$, followed by rinsing twice with distilled water to remove the unattached label.

\section{TIRF microscopy}

The TIRF microscope consists of three components: (1) an inverted microscope with phase-contrast optics (Nikon Diaphot, Tokyo, Japan) mounted on an $x, y$ translating precision milling stage (Setco Industries, Inc., Cincinnati, OH); (2) a custom built $x, y$ translating sample stage that accommodates and positions the TIRF flow cell in the focal plane of the microscope; and (3) a rotation goniometer (Melles Griot, Irvine, CA) that accommodates a single-mode optical fiber cable (Oz Optics, Carp, Ontario, Canada) for 


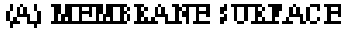

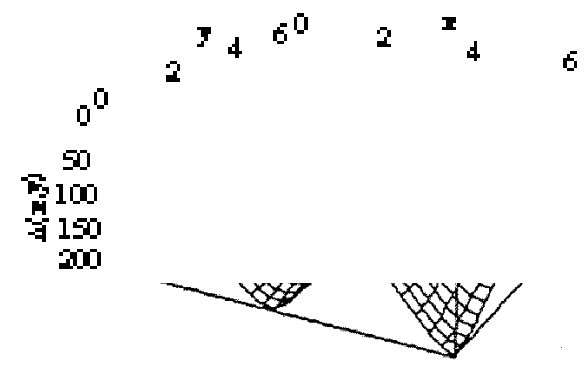

(B) 3D TIRF IMAGE, $70 \mathrm{deg}$

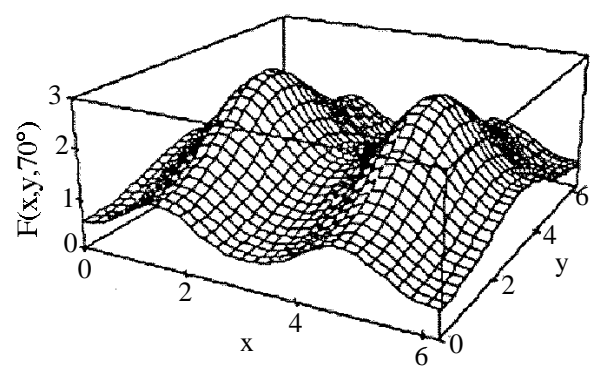

Fig. 2. (A) A $2 \pi \times 2 \pi$ section of the cell membrane with a membrane/substratum separation distance that varies sinusoidally according to the expression $\Delta(x, y)=100\left[\cos ^{2}(x)+\cos ^{2}(y / 2)\right] \mathrm{nm}$, where $0 \leq x, y \leq 2 \pi$. (B) The 3D TIRFM image expected when the cell membrane is evanescently illuminated at an incident angle of 70 degrees.

directing the laser light onto the flow cell at a precisely selected angle of incidence (Fig. 3). The TIRF flow cell consists of an aluminum and Lucite frame that clamps in place two standard 1 in $\times 3$ in $\times 1 \mathrm{~mm}$ soda lime glass microscope slides $(n=1.51$; Gold Seal, Clay Adams, Lincoln Park, NJ) separated by a 0.02 in thick medical grade rubber gasket (Dow Corning, Midland, MI). A truncated hemi-cylindrical prism (BK-7 glass, $n=1.522$, Harrick Scientific, Ossining, NY) was optically coupled to the upper sample containing microscope slide of the flow cell using type DF immersion oil $(n=1.518 \pm 0.002$; Cargille, Cedar Grove, NJ). Solutions were infused into the flow cell volume $(\sim 1.5 \mathrm{ml})$ through ports milled into the Lucite frame; $514.5 \mathrm{~nm}$ light from an $\mathrm{Ar}^{+}$laser (Ion Laser, Salt Lake City, UT) was focused into the fiber cable and directed to an optical rail mounted on the rotation goniometer. The divergent, Gaussian laser light exiting the fiber was collimated by an achromatic lens to a $2.2 \mathrm{~mm}$ beam diameter, filtered to TE polarization, and directed onto the surface of the hemi-cylindrical prism, thus producing an evanescent wave in the region of the fluorescent sample on the bottom surface of the upper glass slide.

\section{Sample alignment and image collection}

The assembled flow cell with sample was centered in the optical axis of the microscope by aligning the phase-contrast optics and objective of the microscope with the central axis of the hemi-cylindrical prism. The $514.5 \mathrm{~nm}$ laser light was then directed into the prism, followed by centering the TIRF spot. Once aligned, the $\times 40$ objective was rotated into place, and a suitable region of the sample was located by translating the TIRF spot up and down the optical axis of the $1 \mathrm{~cm}$ wide hemi-cylindrical prism ( $y$ axis, Fig. 3). Microscope images (TIRFM and phase-contrast) were collected through the bottom glass slide of the flow cell by the $\times 40$ objective, directed through a $514.5 \mathrm{~nm}$ rejection filter and out the video port with $a \times 3.1$ rifle magnifier (Diagnostic Instruments Inc., Sterling Heights, MI) and imaged onto a thermoelectrically cooled Star 1 CCD camera (Photometrics, Tucson, AZ) to produce a pixelized bit map

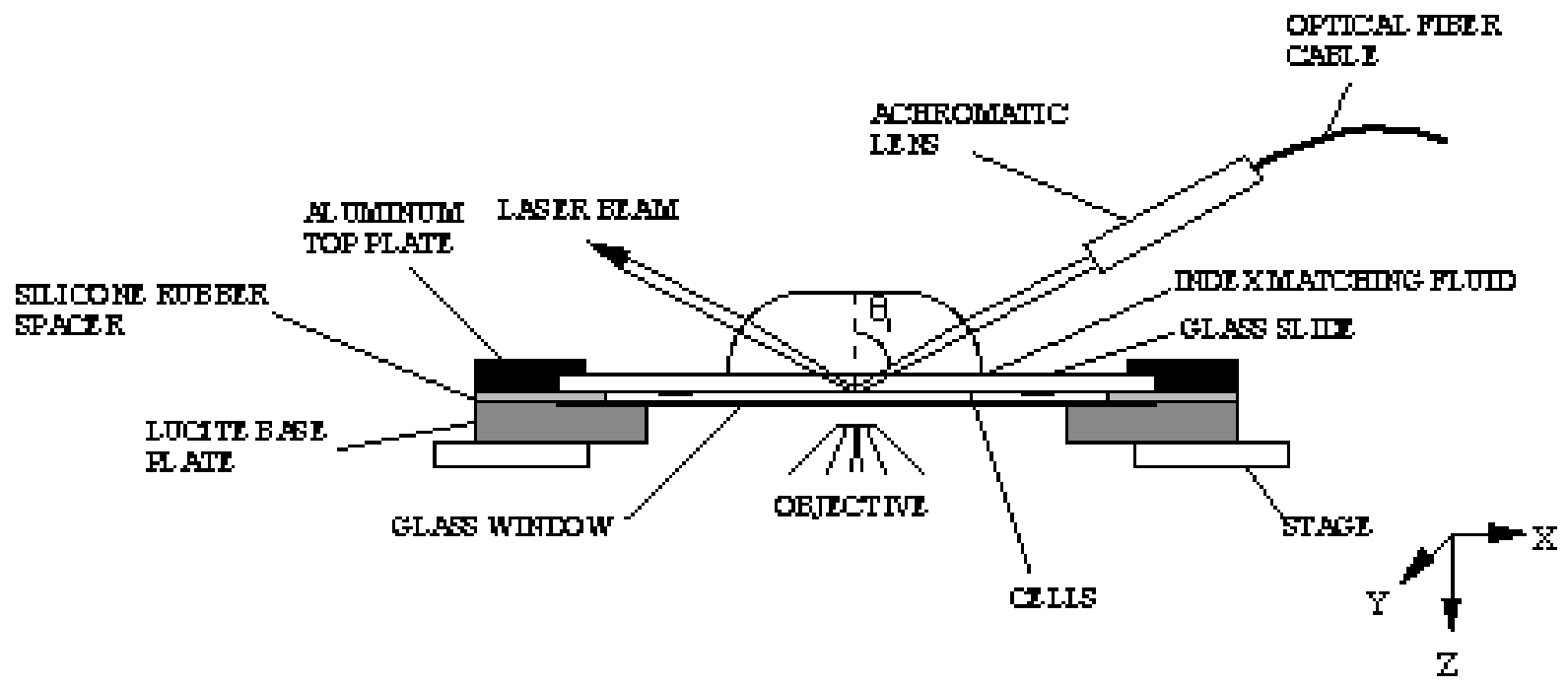

Fig. 3. TIRFM flow cell. 
of image intensities. Image processing was performed on a Mac IIx computer equipped with Ultimage (GTFS Inc., Santa Rosa, CA) software. Photographs of TIRFM and phase-contrast images were taken directly from the video screen.

\section{Scanning electron micrograph (SEM) preparation}

BAEC were plated onto clean glass slides preincubated with $10 \mu \mathrm{g} / \mathrm{ml}$ fibronectin as described. At the end of the incubation, the cells were fixed with $3.7 \%$ formaldehyde, dehydrated in graded ethanol solutions, critical point dried from $\mathrm{CO}_{2}$, and coated with a $20 \mathrm{~nm}$ thick layer of gold in a Hummer V sputter coater for $4 \mathrm{~min}$. Samples were viewed on a Philips 501 scanning electron microscope at $15 \mathrm{keV}$.

\section{Immunofluorescence microscopy of vinculin-stained cells}

Vinculin was visualized by indirect immunofluorescence with a monoclonal antibody raised against chicken gizzard vinculin (hVin-1; Sigma) and a rhodamine-labelled goat anti-mouse IgG. Fixed BAEC were permeabilized with 5\% Triton. After rinsing cells with PBS containing $2 \%$ goat serum and $0.2 \% \mathrm{BSA}$, cells were incubated for $30 \mathrm{~min}$ with the primary antibody at a dilution of 1:50. The cells were rinsed twice with PBS containing $2 \%$ goat serum and $0.2 \%$ BSA and the secondary antibody was added at a dilution of 1:25. After staining, the slides were washed twice with PBS. A $50 \mu \mathrm{l}$ sample of a 1:1 solution of PBS and glycerol was placed on the slide, a coverslip mounted and sealed with nail polish.

\section{Results}

\section{Relative cell/surface separation distances}

Shown in Fig. 4 are phase-contrast and TIRFM images of BAEC plated onto a glass substratum for $15 \mathrm{~min}, 30 \mathrm{~min}$ and $24 \mathrm{~h}$. Cells plated for $15 \mathrm{~min}$ are in the early stages of the attachment and spreading process and the cell shown in Fig. 4A and B is representative of the observed phase-contrast and TIRFM images. The cell shapes observed under phase-contrast microscopy appear rounded (radius of 1026 cells: $7.6 \pm 1.4 \mu \mathrm{m})$. The TIRFM images show a lack of an established contact morphology as evidenced by an image brightness that declines from the cell center. The TIRFM images are very different from the epifluorescent images that show uniform illumination of the cell (not shown). By 30 min the cell has begun to spread (Fig. 4C) and the area of fluorescence has increased significantly (Fig. 4D). The TIRFM fluorescence pattern has become more complicated, with several locations of increased intensity, suggesting that multiple contacts are forming. BAEC plated for $24 \mathrm{~h}$ show an extended and flattened morphology characteristic of a well-spread anchorage-dependent cell (Fig. 4E). The TIRFM image of the cell plated for $24 \mathrm{~h}$ (Fig. 4F) has numerous bright striations characteristic of a well-established network of focal contact formations.

The white lines in Fig. 4B, D and F represent sections of the TIRFM images used to perform a representative series of membrane/substratum separation distance calculations across the width of the cells. The results of these calculations are presented in Fig. 5A-C on both the nanometer and micrometer scales. The separation distances were calculated from equation (9) by scaling all intensities to the brightest regions of the TIRFM image of the cell for an effective refractive index of 1.38 and a minimum separation distance of $\Delta_{\mathrm{o}}=15 \mathrm{~nm}$. Although somewhat arbitrary, a minimum separation distance of $15 \mathrm{~nm}$ is consistent with that reported for focal contacts, and the membrane/substratum separation one might expect for a protein-coated membrane adhering to a protein-coated substratum (Chen and Singer, 1982; Izzard and Lochner, 1976).

The cell adherent for $15 \mathrm{~min}$ shows a narrow region of closest contact which lies beneath the cell center (Fig. 5A). Beyond this region, the cell membrane declines gradually away from the surface and at the cell edge is only about $200 \mathrm{~nm}$ from the surface. A second contact may be in the process of forming near the first contact. After $30 \mathrm{~min}$ of attachment, only a single small contact is formed near the surface, but a broader region of the cell is within $100 \mathrm{~nm}$ of the surface (Fig. 5B). Undulations in the membrane suggest that additional contacts are forming.

By $24 \mathrm{~h}$ the cell membrane exhibits several undulations of the order of $200 \mathrm{~nm}$ separated by $0.5-5 \mu \mathrm{m}$ wide regions of closest contact (Fig. 5C). The distance between closest and furthest cell membrane separations from the substratum are consistent with the known distance between focal contacts and extracellular matrix contacts (Burridge et al., 1988). When sections are taken along the long axis of the focal contact, the contacts are 5-10 $\mu \mathrm{m}$ long and separated by $5-10 \mu \mathrm{m}$. The relative distance plots indicate that the cell membrane is nearest the surface only in the immediate vicinity of the focal contact. Note, however, the ventral surfaces of all three cells (15 min, $30 \mathrm{~min}$ and $24 \mathrm{~h}$ ) appear to be essentially flat when viewed on the micrometer length scale. Thus, even near the cell periphery of the most rounded 15 min cell, the cell ventral membrane is still close to the surface.

\section{Topographical maps of contact regions}

TIRF patterns of the entire ventral surfaces of cells plated for $15 \mathrm{~min}, 30 \mathrm{~min}$ and $24 \mathrm{~h}$ were converted into topographical maps as follows. Separation distances were determined again by equation (9) for $\Delta_{0}=15 \mathrm{~nm}$, and separation distances from the substratum surface of less than 15 $\mathrm{nm}$, between 15 and $50 \mathrm{~nm}$, and between 50 and $100 \mathrm{~nm}$ were assigned the colors of red, yellow and blue, respectively. These regions correspond to focal, close and extracellular matrix contacts for well-spread cells. The results of this transformation are presented in Fig. 6A-C, which are three-dimensional analogs of Fig. 5A-C.

The map for the 15 min cell (Fig. 6A) shows a concave downward cell membrane with a gradated and nearly radial decrease in separation distances from the cell center. By 30 min, the contact pattern is less regular, indicating that multiple contacts are forming with the surface (Fig. 6B). The map for the $24 \mathrm{~h}$ cell (Fig. 6C) shows the majority of the cell membrane within $100 \mathrm{~nm}$ of the substratum surface with numerous and discrete focal contacts located primar- 
ily beneath the cell interior. Close contacts of $50 \mathrm{~nm}$ or less are closely associated with the focal contacts in the cell interior and located along the cell perimeter.

Of particular interest is the possible observation of nascent focal contacts in the 30 min cell (Fig. 6B). Using the forward TIRF transform (eqn (8)), it is possible to threshold the TIRFM images of the cell and calculate the cell areas within certain distances from the surface. This was done for cells attached for 15 and $30 \mathrm{~min}$ (Table 1). The calculated areas clearly show that as the cell begins to spread on the surface, a greater percentage of the cell underside is in close contact with the surface. Interestingly, only a small percentage of the cell membrane was within $30 \mathrm{~nm}$ of the surface by $30 \mathrm{~min}$.
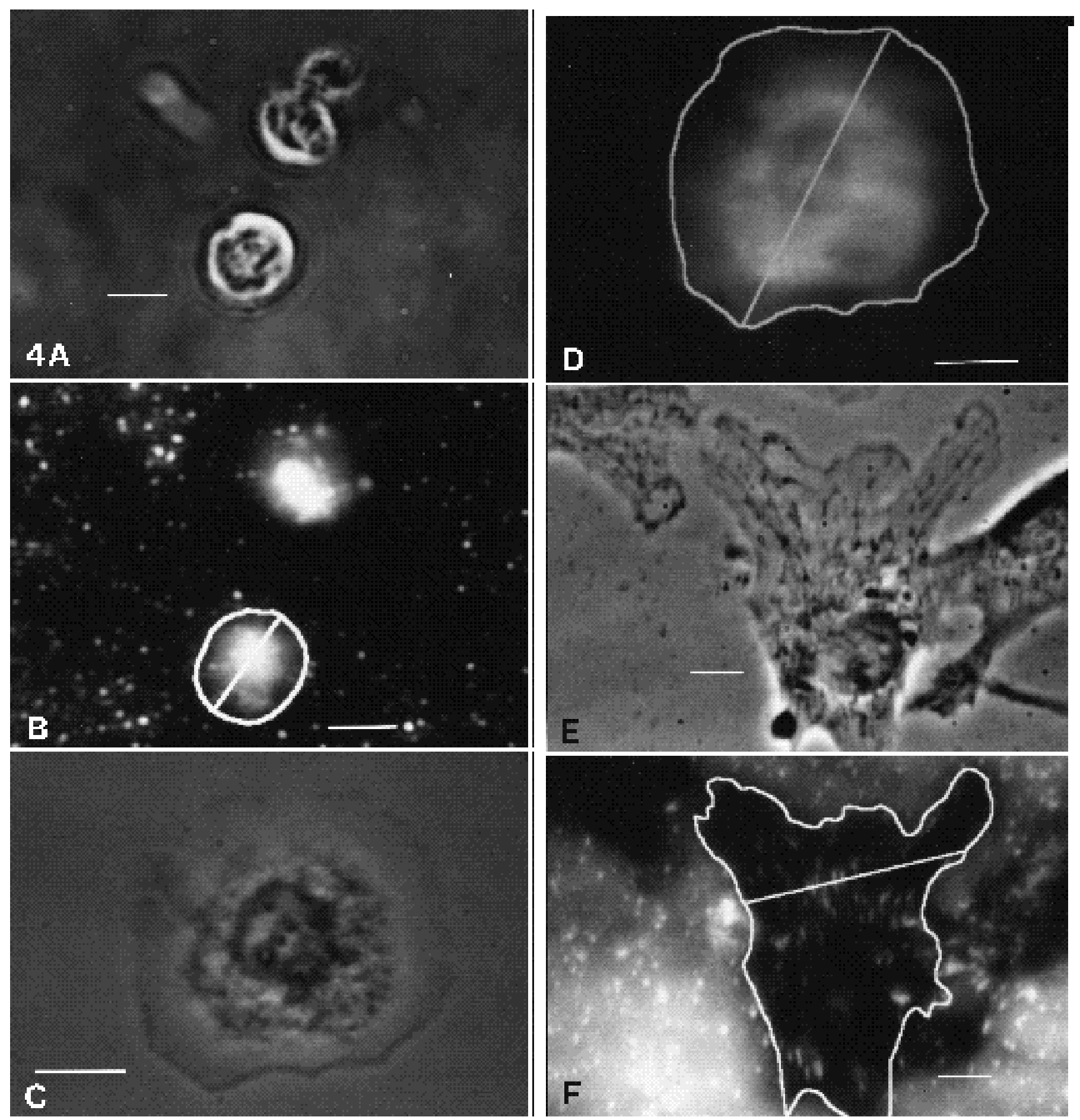

Fig. 4. Phase-contrast images of BAEC: (A) $15 \mathrm{~min}$, (C) $30 \mathrm{~min}$, and (E) $24 \mathrm{~h}$ after plating. Bar, $10 \mu \mathrm{m}$. Corresponding TIRFM images of BAEC: (B) $15 \mathrm{~min}$, (D) $30 \mathrm{~min}$, and (F) $24 \mathrm{~h}$ after plating. Bar outside of cell, $10 \mu \mathrm{m}$. 

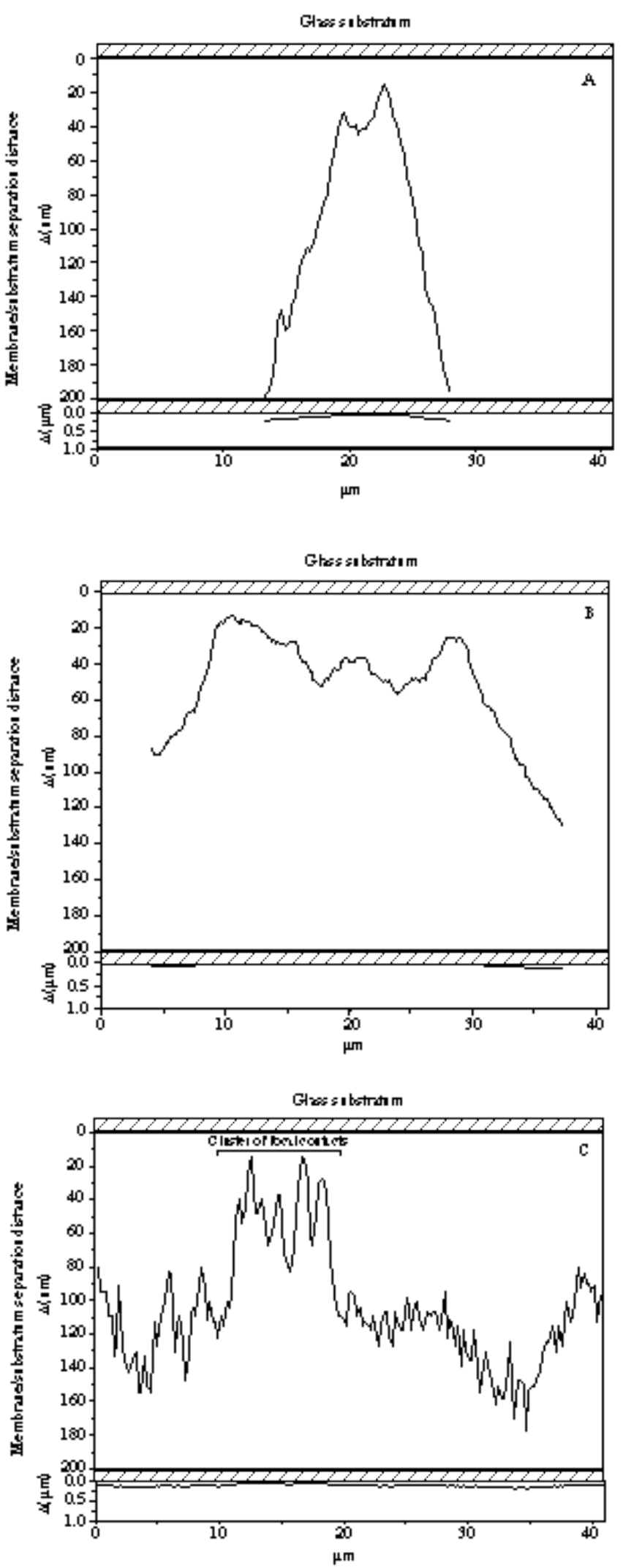

Fig. 5. Relative separation distances across cells plated for (A) 15 min, (B) $30 \mathrm{~min}$, and (C) $24 \mathrm{~h}$.
Correspondence between TIRFM, SEM and

immunofluorescence images

Scanning electron and immunofluorescence microscopy were employed to address two aspects of our TIRFM results: (i) the presence of a flat ventral surface at $15 \mathrm{~min}$ and (ii) the observation of a mature focal contact pattern only in the $24 \mathrm{~h}$ cell.

Scanning electron micrographs (SEMs) were obtained for cells attached to glass for 15 min. From an observation angle of 0 degrees, which corresponds to an overhead view of the cell, the cells have the characteristic rounded shape observed in phase-contrast microscopy (Fig. 7A). At an observation angle of 60 degrees, a side of the cell in contact with the surface is visible, which is often a broad and flattened region roughly the width of the cell, which is the size predicted by TIRFM (Fig. 7B). All cells examined exhibited this morphology, which deviates significantly from a completely spherical shape inferred from phase-contrast microscopy. These observations agree with previous studies (Bereiter-Hahn et al., 1990; Heaysman et al., 1982; Grinnell et al., 1976) showing that cells rapidly develop flat ventral surfaces after contact with the surface.

Immunofluorescent staining of vinculin was used to identify focal contacts in identically plated cells (Burridge et al., 1988). Cells attached for 15 and 30 min failed to show any increase in vinculin staining above background levels, but vinculin-stained focal contacts could be identified after $2 \mathrm{~h}$ of attachment (not shown). By $24 \mathrm{~h}$, well-developed focal contacts are visible (not shown). The pattern of vinculin immunofluorescence is similar to that observed with cells examined with TIRFM. Immunofluorescent-stained vinculin was also viewed under TIRF illumination, which is consistent with the location of vinculin in focal contacts approximately $15 \mathrm{~nm}$ from the surface.

\section{Discussion}

In this paper, TIRFM images were used to calculate relative separation distances of the ventral membrane of BAEC following $15 \mathrm{~min}, 30 \mathrm{~min}$ and $24 \mathrm{~h}$ attachment to a Fncoated glass surface. The basis for developing a method of quantifying TIRFM images comes from recent reports in

Table 1. Area of the cell at different distances from the

\begin{tabular}{lccc}
\multicolumn{3}{c}{ surface } \\
\hline \multirow{2}{*}{$\begin{array}{l}\text { Incubation } \\
\text { time }(\mathrm{min})\end{array}$} & $15-30 \mathrm{~nm}$ & $30-65 \mathrm{~nm}$ & $\begin{array}{c}\text { Area }\left(\mu \mathrm{m}^{2}\right) \\
\left(\mu \mathrm{m}^{2}\right)^{*}\end{array}$ \\
\cline { 2 - 4 } $15(N=7) \dagger$ & $3.3 \pm 2.8 \ddagger$ & $12.6 \pm 9.2 \S$ & $152 \pm 22$ \\
& $(0.027 \pm 0.023) \mathbb{4}$ & $(0.080 \pm 0.029$ & \\
$30(N=9)$ & $11.2 \pm 4.0 \ddagger$ & $134 \pm 113 \S$ & $512 \pm 441$ \\
& $(0.042 \pm 0.034)$ & $(0.29 \pm 0.13)$ &
\end{tabular}

*Projected area of the cell observed under phase-contrast illumination. $\dagger N$ represents the number of cells examined.

$\ddagger P<0.001$ by Student's $t$-test.

$\$ 0.01<P<0.025$ by Student's $t$-test.

IV Values in parentheses represent the ratio of the area measured under TIRFM illumination relative to the projected area. 

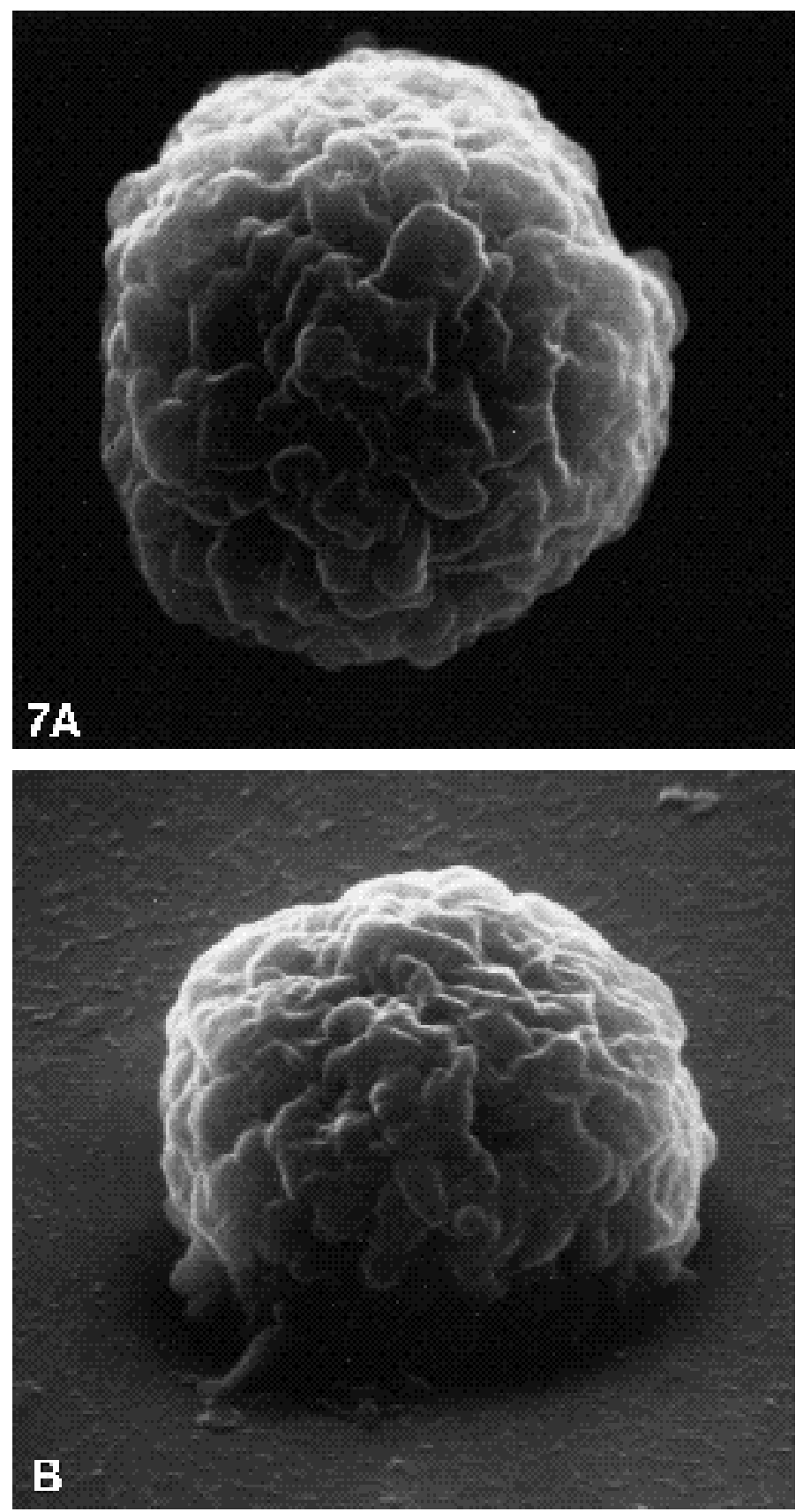

Fig. 7. SEM of a BAEC plated for 15 min viewed at (A) 0 degrees (B) 60 degrees from normal. $\times 5,600$.

which (i) separation distances for focal and close contacts were obtained from photometric measurements using two angles of TIRF illumination (Lanni et al., 1985), and (ii) a more straightforward method of calculating relative and absolute separation distances was developed (Reichert and Truskey, 1990). Owing to the method of data collection, the analysis of Lanni et al. (1985) was limited to a few regions of the cell membrane and the calculation method was cumbersome. In the current study, digital images were acquired, permitting a topographical mapping of membrane/substratum separations over the entire ventral surface of the cell. However, we assumed a minimum separation of $15 \mathrm{~nm}$. Therefore, our calculations yield only relative values of membrane/substratum separations. This weakness in our analysis will be addressed in a future publication concerning variable angle TIRFM depth profiling of focal contacts (Burmeister et al., in preparation).

Support for the validity of our digitized TIRFM images comes from the correspondence between TIRFM and other measures of cell-surface contact. At $15 \mathrm{~min}$, the TIRFM image showed that a relatively flat region of the cell was in contact with the surface and the contact region was much broader than expected if a spherical cell contacted the surface. This observation was consistent with the SEM images of a 15 min cell showing a large disk-like cellular projection in close apposition with the surface. However, TIRFM provides the added information that only a very small region near the cell center was within $50 \mathrm{~nm}$ of the surface. This same pattern of contact was observed for all cells examined at 15 min (Bereiter-Hahn et al., 1990: Heaysman et al., 1982; Grinnell et al., 1976). Although technically difficult, transmission electron microscopy and TIRFM images of the same cell would have provided direct verification of the contact region.

The separation distances after 30 min of contact with the surface indicate that the contact area has increased significantly from $15 \mathrm{~min}$, and the cell is coming into contact with the surface at multiple locations. Similar observations have been made by TIRFM for rat basophilic leukemia cells (Nakache et al., 1986), and IRM of spreading endothelial cells (Bereiter-Hahn et al., 1990). Focal contacts do not appear to have formed yet, since no elliptical regions of very intense fluorescence were observed, which is consistent with the known dynamics of focal contact formation (Burridge et al., 1988; Izzard and Lochner, 1976; Chen and Singer, 1982; Bereiter-Hahn et al., 1990).

After $24 \mathrm{~h}$ of attachment, focal contacts could be identified by both TIRFM and vinculin staining. Focal contacts on TIRFM images showed the characteristic striated appearance and orientation of focal contacts identified using IRM, TIRFM and immunofluorescent staining of adhesion protein receptors. The calculated distances between closest and farthest separation from the surface are consistent with the known separation between focal and close contacts. The TIRFM images indicate that the majority of the membrane surrounding the focal contact is greater than $50 \mathrm{~nm}$ from the substratum surface.

Finally, focal contacts identified morphologically in the TIRFM images are not all of the same brightness. This indicates that not all focal contacts are the same, which is consistent with observations that the lifetimes of focal contacts are variable (Burridge et al., 1988). In terms of our quantitation scheme, the variable brightness suggests that focal contacts can have slightly different membrane/substratum separations. Alternatively, variations in the intensity of focal contacts could represent different amounts of dye incorporated into the membrane of the focal contact due to exclusion of the dye by the high receptor concentration. Therefore, one needs to consider a possible spurious influence of carbocyanine dye aggregates (Vaidyanathan et al., 1985) on the TIRFM images.

Under this view, regions of intense fluorescence represent sites of dye aggregation and regions of diminished flu- 
orescence represent regions of dye exclusion. However, this possibility may be inconsistent with the currently held image of focal contacts having a high concentration of adhesion protein receptors in the cell membrane and a concomitant local exclusion of membrane lipid. Since the lipophilic carbocyanine dye is embedded in the membrane (Axelrod, 1979), a locally high protein concentration would also exclude the dye from the focal contact. In spite of a possibly reduced dye concentration in the focal contact, these regions are still the most intensely fluorescent regions of the membrane when viewed by TIRFM. Furthermore, the immunofluorescence images of vinculin-stained focal contacts in the $24 \mathrm{~h}$ cells showed the same striated image brightness pattern as the $24 \mathrm{~h}$ TIRFM images, which argues against dye aggregates producing locally bright spots which are mistaken for focal contacts.

In general, our results support the contention of Gingell et al. (1987) that TIRFM is well suited for observing the small fluctuations in the contour of membrane/substratum contact regions. Specifically, we used simplified theoretical fits to the TIRFM image brightness to construct topographical maps of relative cell separations over the entire ventral surface of BAEC plated for $15 \mathrm{~min}, 30 \mathrm{~min}$ and 24 h. The BAEC plated for $24 \mathrm{~h}$ had a well-spread morphology where the relative separation distance between the focal contact and the cell membrane was of the order of $100 \mathrm{~nm}$. The cell plated for $15 \mathrm{~min}$ was rounded, but had a flattened ventral membrane with a central point of closest contact and a separation of approximately $200 \mathrm{~nm}$ at the cell periphery. The cell plated for $30 \mathrm{~min}$ was still somewhat rounded but showed signs of initial cell spreading and nascent focal contact formation. From this demonstration it appears that quantitative TIRFM can provide useful information on the focal contact morphology of adherent BAEC under variable conditions of cell attachment and growth.

This work was supported from the NIH grants HL 32132 and HL 44972, and a biomedical research grant from the Whitaker Foundation. We gratefully acknowledge the helpful comments from S.S. Saavedra of the University of Arizona, as well as the technical assistance of Ms. Patsy Seay.

\section{References}

Axelrod, D. (1979). Carbocyanine dye orientation in red cell membrane studied by microscopic fluorescence polarization. Biophys. J. 26, 557574 .

Axelrod, D., Fullbright, R.W. and Hellen, E.H. (1986). Adsorption kinetics on biological membranes: measurement by total internal reflection fluorescence. In Applications of Fluorescence in the Biomedical Science (ed. D.L. Taylor, A.S. Waggoner, F. Lanni, R.F. Murphy and R.R. Birge), pp. 461-476. A. R. Liss, Inc., NY.

Axelrod, D., Thompson, N.L. and Burghardt, T.P. (1982). Total internal reflection fluorescence microscopy. J. Microsc. 129, 19-28.

Bereiter-Hahn, J.C., Fox, H. and Thorell, B. (1979). Quantitative reflection contrast microscopy of living cells. J. Cell Biol. 82, 767-779.

Bereiter-Hahn, J.C., Luck, M., Miebach, T., Stelzer, H.K. and Voth, M.
(1990). Spreading of trypsinized cells: cytoskeletal dynamics and energy requirements. J. Cell Sci. 96, 171-188.

Burridge, K., Fath, K., Kelly, T., Nuckolls, G. and Turner, C. (1988). Focal adhesions: transmembrane junctions between the extracellular matrix and the cytoskeleton. Annu. Rev. Cell Biol. 4, 487-525.

Chen, W.T. and Singer, S.J. (1982). Immunoelectron microscopic studies of the sites of cell-substratum and cell-cell contacts in cultured fibroblasts. J. Cell Biol. 95, 205-222.

Gingell, D. and Todd, I. (1979). Interference reflection microscopy. A quantitative theory for image interpretation and its application to cellsusbtratum separation measurements. Biophys. J. 26, 507-526.

Gingell, D., Todd, I. and Bailey, J. (1985). Topography of cell-glass revealed by total internal reflection of volume markers. J. Cell Biol. 100, 1334-1338.

Gingell, D., Heavens, O.S. and Mellor, J.S. (1987). General electromagnetic theory of total internal reflection fluorescence: the quantitative basis for mapping cell-substratum topography. J. Cell Sci. 87, 677-693.

Grinnell, F., Tobleman, M.Q. and Hackenbrock, C.R. (1976). Initial attachment of baby hamster kidney cells to an epoxy surface. J. Cell Biol. 70, 707-713.

Heaysman, J.E.M., Pegrum, S.M. and Preston, T.M. (1982). Spreading chick heart fibroblasts. A correlated study using phase contrast microscopy, RIM, TEM and SEM. Exp.Cell Res. 140, 85-93.

Izzard, C.S. and Lochner, L.R. (1976). Cell-to-substrate contacts in living fibroblasts: an interference reflexion study with an evaluation of the technique. J. Cell Sci. 21, 129-159.

Lanni, F., Waggoner, A.S. and Taylor, D.L. (1985). Structural organization of interface 3T3 fibroblasts studies by total internal reflection fluorescence microscopy. J. Cell Biol. 100, 1091-1102.

Nakache, M., Gaub, H. E., Schreiber, A. B. and McConnell, H.M. (1986). Topological and modulated distribution of surface markers on endothelial cells. Proc. Nat. Acad. Sci.USA 83, 2874-2878.

Reichert, W.M. (1989). Evanescent detection of adsorbed protein films: assessment of optical considerations for absorbance and fluorescence spectroscopy at the crystal/solution and polymer/solution interfaces. Crit. Rev. Biocompat. 5, 173-205.

Reichert, W.M. and Truskey, G.A. (1990). Total internal reflection fluorescence (TIRF) microscopy. I. modelling of cell contact region fluorescence. J. Cell Sci. 96, 219-230.

Roboteskewyj, A., McKibben, S., Dull, R., Griem, M.L. and Davies, P.F. (1991). Dynamics of focal adhesion site remodelling in living endothelial cells in response to shear stress forces using confocal image analysis. FASEB J. 6, 906.

Ruoslahti, R., Hayman, E.G., Pierschbacher, M. and Engvall, E. (1982). Fibronectin: purification, immunochemical properties, and biological activities. Meth. Enzymol. 82, 803-831.

Todd, I., Mellor, J.S. and Gingell, D. (1988). Mapping cell-glass contact of Dicytostelium amoebae by total internal reflection aqueous fluorescence overcomes a basic ambiguity of interference reflection microscopy. J. Cell Biol. 89, 107-114.

Truskey, G.A. and Pirone, J.S. (1990). The effect of fluid shear stress upon cell adhesion to fibronectin-treated surfaces. J. Biomed. Mater. Res. 24, 1333-1353.

Vaidyanathan, S., Patterson, L.K., Mobius, D. and Gruniger, H.R. (1985). Effect of monolayer composition and organization on fluorescent behavior. J. Phys. Chem. 89, 491-497.

Weis, R. M., Balakrishnan, K., Smith, B. A. and McConnell, H. M. (1982). Stimulation of fluorescence in a small contact region between rat basophil leukemia cells and planar lipid membrane targets by coherent evanescent radiation. J. Cell Biol. 257, 6440-6445.

Yamada, K.M. (1982). Isolation of fibronectin from plasma and cells, In Immunochemistry of the Extracellular Matrix, vol. 1 (ed. H. Furthmayr), pp. 111-123. CRC Press, Boca Raton.

(Received 27 April 1992 - Accepted 16 June 1992) 
6393 colour tipin

Fig. 6. Ventral surface topographic map of BAEC $15 \mathrm{~min}, 30 \mathrm{~min}$, and $24 \mathrm{~h}$ after plating. Separation distances of $<15$, $<50 \mathrm{and}<100 \mathrm{~nm}$ from the substratum surface correspond to the colors of red, yellow and blue, respectively. Bar, $10 \mu \mathrm{m}$. 